
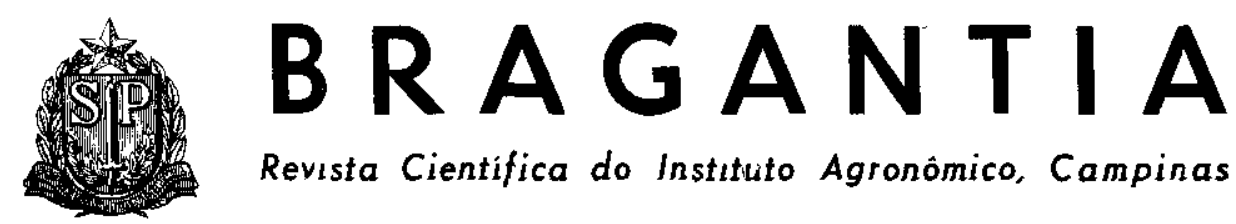

Revista Cientifica do Instıtuto Agronômico, Campinas

\title{
COMPORTAMENTO DE CULTIVARES COMERCIAIS DE PESSEGUEIRO COMO PORTA-ENXERTO (')
}

Mário Ojima, Oruando Rigitano, Seção de Fruticultura de Clima Temperado, Sebastĩ̃o Alves, Estação Experimental de Monte Alegre do Sul, Fernando Antonio Campo dall'Orto (2) e Antonio Fernando Caetano Tombolato $\left({ }^{2}\right)$, Seção de Fruticultura de Clima Temperado, Instituto Agronômico.

O pessegueiro é normalmente propagado por enxertia sobre os "seedlings" da própria espécie, admitindo-se, no entanto, em condiçōes especiais de clima e solo, outras rosáceas do gênero Prunus como porta-enxerto (2). O Instituto Agronômico vem estudando - comportamento de pessegueiros, com o uso de cultivares-copa e porta-enxerto escolhidos dentre o material em cultivo comercial e as seleções IAC de pêssegos mais promissores para o Estado. Em experimento conduzido na Estação Experimental de Jundiaí, verificou-se que não houve influência dos porta-enxertos na produtividade e nos hábitos vegetativos das plantas (1). O presente trabalho relata os resultados obtidos em experimento similar, desenvolvido nas condições ecológicas de Monte Alegre do Sul.
Material e métodos: 0 trabalho foi conduzido na Estação Experimental de Monte Alegre do Sul, do Instituto Agronômico, localizada a $777 \mathrm{~m}$ de altitude e apresentando as seguintes médias de chuvas e temperaturas: precipitaçōes pluviais anuais, $1.469 \mathrm{~mm}$; precipitações mensais, $48 \mathrm{~mm}$, no período mais seco (abril a setembro); temperatura média anual, $19,5^{\circ} \mathrm{C}$, dos meses mais frios, $15,9^{\circ} \mathrm{C}$ (junho e julho), e dos meses mais quentes, $22,1^{\circ} \mathrm{C}$ (janeiro e fevereiro).

$O$ lote experimental foi instalado em terreno com leve inclinação, em solo podzólico vermelho-amarelo, orto, unidade Monte Alegre (4).

Quatro cultivares de pessegueiro - 'Talismā' (IAC 1353-11), 'Ouromel' (IAC 2-76), 'Rei-da-

(I) Recebido para publicação a 11 de dezembro de 1979.

(") Com bolsa de suplementação do CNPq. 
-Conserva' e 'Campinas-1' - foram estudados, enxertando-os sobre "seedlings" de diversos cultivares.

'Talismã' contou com 19 porta-enxertos: 'Rei-da-Conserva', 'Hall's Yellow', 'Maracotão Branco', 'Sangüíneo', 'Cristal' (IAC 159-1), 'Alô-Doçura' (IAC 159-1A1), 'Colibri' (IAC 159-1-A4), 'Tutu' (IAC 1353-1), 'Relíquia' (IAC 1353-10), 'Talismã', 'Néctar' (IAC 1453-1), 'IAC 1453-2', 'Delícia' (IAC 1453-4), 'Brasão' (IAC 1153-4), 'IAC 153-3', 'IAC 353-2', 'IAC 151-1', 'IAC 151-2' e 'IAC 651-1'; 'Ouromel' e 'Rei-da-Conserva', cada um com nove: 'Rei-da-Conserva', 'Hall's Yellow', 'Maracotão Branco', 'Sangüíneo', 'Cristal', 'Alố-Doçura', 'Delícia', 'IAC 153-3' e 'IAC 151-1'; e o 'Campinas-1' com sete: 'Rei-da-Conserva', 'Sangüíneo', 'Cristal', 'Alô-Doçura', 'Delícia', 'IAC 153-3' e 'IAC 151-1'.

Dado o número reduzido $\mathrm{e}$ variável de plantas para as diferentes combinações copa/porta-enxerto, os cultivares-copa foram plantados em lotes distintos, porém contíguos. Dentro de cada cultivar-copa, fez-se o delineamento em blocos ao acaso, com duas repetições; as parcelas experimentais, representadas por porta-enxertos, foram constituídas de apenas uma planta. Procurou-se, assim, estudar o efeito do porta-enxerto para cada cultivar-copa, não visando à comparação de cultivares-copa entre si.

A instalação do experimento efetuou-se em agosto de 1964, adotando-se o espaçamento de $6 \times 4 \mathrm{~m}$; as mudas, de raiz nua, foram plantadas em covas previamente adubadas. Nos anos subseqüentes, foram proporcionados ao pomar cuidados normais ao molde de uma cultura (3), constituídos de condução das plantas em forma de taça, podas de formação e de frutificação, desbaste e ensacamento dos frutos, tratamentos fitossanitários de inverno e de verão, adubações, irrigações e cultivo do solo.

Como no experimento de Jundiaí (1), consideraram-se, no presente estudo, as produções relativas a cinco anos consecutivos 1967 a 1971 - em plantas de três a sete anos de idade, período de formação do pessegal, que apresenta aumentos graduais na frutificação, até atingir a fase adulta.

Resultados e conclusões: As plantas apresentaram desenvolvimento normal no período considerado, não revelando nenhuma diferença apreciável entre si que sugerisse a influência do porta-enxerto, tanto no vigor como no crescimento do tronco e da copa. Os ciclos vegetativo e frutífero apresentaram-se também uniformes. Os cultivares Talismã e Ouromel tiveram um máximo de produção em novembro, eventualmente em fins de outubro e início de dezembro, enquanto 'Rei-da-Conserva' e 'Campinas-1' mostraram colheitas maiores em dezembro e reduzidas em novembro e janeiro.

As produções foram satisfatórias, tendo em vista as características de cada cultivar e a menor área ocupada por planta $-24 \mathrm{~m}^{2}$, 
que corresponde a $2 / 3$ da adotada na prática. Para se ter uma idéia geral, são apresentadas no quadro 1 as produções médias por planta e por cultivar-copa, nos cinco anos sucessivos de controle. Esses dados indicam que os cultivares Talismã e Rei-da-Conserva mostraram-se bem mais produtivas que Campinas-1 e Ouromel, fato esse também constatado em culturas comerciais.

Nos quadros 2 e 3 estão anotadas as produções médias anuais por planta, em número e peso de frutos colhidos, e peso de um fruto, no qüinquiênio $1967 / 71$, relativas a cada cultivar-copa e porta-enxerto. Verifica-se que, dentro de cada cultivar-copa, tanto as produções como o peso de um fruto mantiveram-se em torno da média, não indicando a influência do porta-enxerto.

Em face desses resultados e tendo em vista os anteriormente obtidos na Estação Experimental de Jundiaí (1), com a adoção de tratamentos similares, que não mostraram diferenças significativas para os porta-enxertos, dispensou-se a análise estatística no presente trabalho. 0 exame das produções anuais nas diferentes combinações enxerto/porta-enxerto, também não mostrou diferenças sensíveis entre os tratamentos; aí, as maiores discrepâncias foram notadas em algumas plantas, em determinado ano, as quais se compensavam em outras safras.

Os dados ora obtidos ratificam a conclusão exposta no trabalho anterior (1), ou seja, qualquer dos porta-enxertos referidos poderá ser empregado, sem inconvenientes para o desenvolvimento e produtividade das plantas, em culturas comerciais de pessegueiro dos quatro cultivares estudados. Isto é de grande significado prático, ao proporcionar liberdade na escolha de material para porta-enxerto.

QUADRO 1 - Produçóes médias sucessivas, por planta e por ano, relativas a quatro cultivares de pessegueiro enxertados sobre diversos porta-enxertos, no periodo $1967 / 71$

\begin{tabular}{ccccc} 
Ano & 'Talismā' & 'Ouromel' & $\begin{array}{c}\text { 'Rei da } \\
\text { Conserva' }\end{array}$ & 'Campinas-1' \\
\hline & $\mathrm{kg}$ & $\mathrm{kg}$ & 37,2 & $\mathbf{k g}$ \\
1967 & 24,2 & 16,5 & 40,3 & 21,5 \\
1968 & 35,7 & 12,1 & 54,4 & 45,3 \\
1969 & 54,0 & 24,4 & 34,8 & 29,2 \\
1970 & 39,9 & 4,0 & 50,2 & 44,2 \\
1971 & 71,4 & 38,5 & 4
\end{tabular}


QUADRO 2 - Produçǟo média anual, no qüinqüênio 1967/71. em número e peso de frutos, e peso de um fruto, relativa ao cultivar Talismã, enxertado sobre diversos porta-enxertos

\begin{tabular}{|c|c|c|c|}
\hline \multirow{2}{*}{ Porta-enxerto } & \multicolumn{2}{|c|}{ Produçāo por planta } & \multirow{2}{*}{$\begin{array}{c}\text { Peso de } \\
\text { um } \\
\text { fruto }\end{array}$} \\
\hline & Frutos & Peso & \\
\hline & n. ${ }^{\circ}$ & kg & $\mathrm{g}$ \\
\hline 'Rei da Conserva' & 476 & 43,9 & 92,2 \\
\hline 'Hall's Yellow' & 435 & 39,7 & 91,1 \\
\hline 'Maracotăo Branco' & $407\left(^{(1)}\right.$ & $35,6\left({ }^{1}\right)$ & $87,2(1)$ \\
\hline 'Sangüíneo' & 474 & 45,5 & 95,8 \\
\hline 'Cristal' (IAC 159-1) & 544 & 46,9 & 86,3 \\
\hline 'Alô-Doçura' (IAC 159-1-A1) & 502 & 46,7 & 92,9 \\
\hline 'Colibri' (IAC 159-1-A4) & $516(1)$ & $49,0^{(1)}$ & $94,9\left({ }^{(1)}\right.$ \\
\hline 'Tutu' (IAC 1353-1) & 472 & 48,4 & 102,6 \\
\hline ‘Relíquia' (IAC 1353-10) & $485(1)$ & $44,7\left(^{1}\right)$ & $92,2\left({ }^{1}\right)$ \\
\hline 'Talismã' (IAC 1353-11) & 480 & 43,6 & 90,9 \\
\hline 'Néctar' (IAC 1453-1) & 577 & 51,4 & 89,1 \\
\hline 'IAC 1453-2' & 519 & 50,7 & 97,7 \\
\hline 'Delicia' (IAC 1453-4) & 486 & 45,5 & 93,5 \\
\hline 'IAC 1153-4' & 428 & 38,6 & 90,1 \\
\hline 'IAC 153-3' & 499 & 48,0 & 96,1 \\
\hline 'IAC 353-2' & $491(1)$ & $46,7\left(^{1}\right)$ & $95,1\left(^{1}\right)$ \\
\hline 'IAC 151-I' & $491\left(^{1}\right)$ & $56,8\left({ }^{(}\right)$ & $115,7\left(^{(1)}\right.$ \\
\hline 'IAC 151-2' & 468 & 43,8 & 93,7 \\
\hline 'IAC 651-1' & 367 & 33,4 & 90,9 \\
\hline Media & 480 & 45,2 & 94,1 \\
\hline
\end{tabular}

(1) Dados relativos a uma planta. 





Vol. 41, Nota $n .^{\circ} 1$

\section{PEACH ROOTSTOCK STUDY}

\section{SUMMARY}

A peach rootstock study was initiated at Monte Alegre do Sul, SP, in 1964, to evaluate the behavior of four peach cultivars: 'Talismä', 'Ouromel', 'Rei da Conserva' and 'Campinas-1', grafted on respectively $19,9,9$ and 7 peach rootstocks. The rootstocks were seedlings of the main commercial peach cultivars planted in São Paulo and of several local peach selections. The results covering the period of $1967 / 71$ did not show any significant difference of performance influenced by the rootstocks studied regarding the tree habit and productivity.

\section{REFERENCIAS BIBLIOGRAFICAS}

1. OJIMA, M.; RIGITANO, O.; SCARANARI, H. J.; MARTINS, F. P.; CAMPO DALL' ORTO, F. A.; NAGAI, V. Estudo de porta-enxertos para o pessegueiro. Bragantia, Campinas, 37:45-52, 1978.

2. RIGITANO, O. A cultura do pessegueiro. Rio de Janeiro, Serviço de Documentação do Ministério da Agricultura, 1945. 116p.

3. — Cultura do pessegueiro. 2.ed. São Paulo, Melhoramentos, 1962, 32p. (ABC do Lavrador Prático, 61)

4. ROTTA, C. L.; JORGE, J. A.; OLIVEIRA, J. B.; KUPPER, A. Levantamento pedológico detalhado da Estação Experimental de Monte Alegre do Sul, SP. Bragantia, Campinas, $30: 215-252,1971$. 